\title{
Auditorium of the future: e learning platform
}

\author{
Hasan F. Batirel ${ }^{1}$, Jalal Assouad ${ }^{2}$, Harry Etienne ${ }^{2}$, Xavier Benoit D'Journo ${ }^{3}$ \\ ${ }^{1}$ Marmara University Hospital, Istanbul, Turkey; ${ }^{2}$ Sorbonne University, Tenon University Hospital, Department of Thoracic and Vascular Surgery, \\ Paris, France; ${ }^{3}$ Aix-Marseille University, Thoracic surgery department, North Hospital, Marseille, France \\ Contributions: (I) Conception and design: HF Batirel, J Assouad, XB D’Journo; (II) Administrative support: HF Batirel; (III) Provision of study \\ materials or patients: All authors; (IV) Collection and assembly of data: HF Batirel, H Etienne; (V) Data analysis and interpretation: All authors; (VI) \\ Manuscript writing: All authors; (VII) Final approval of manuscript: All authors. \\ Correspondence to: Hasan F. Batirel, MD, PhD. Thoracic Surgery Department, Marmara University Hospital, 7. Kat, Gogus Cerrahisi. Fevzi Cakmak \\ Mah., Mimar Sinan Cad., No: 41, 34899, Ust Kaynarca, Pendik, Istanbul, Turkey. Email: hbatirel@marmara.edu.tr.
}

\begin{abstract}
Principles of surgical training have not changed, but methods of training are evolving very fast. Online tools are being adopted in both knowledge and skills training for surgical residents. As a result, to evaluate the outcome of these tools, online assessment is also developing. Knowledge resources are very diverse ranging from lectures, webinars, surgical videos to three-dimensional planning and printing. Skills resources include virtual reality simulators, remote skills training and interdisciplinary teamwork. Assessment of E-learning tools can be performed using online questions, task-based simulations, branching scenarios and online interviews/discussions. In thoracic surgery, video assisted thoracic surgery (VATS) lobectomy simulator has been developed and it appears to be an important tool for minimally invasive thoracic surgery education. Training programs incorporate e-Learning in their curriculum and online training and assessment will become an important part of thoracic surgical training as well.
\end{abstract}

Keywords: E-learning; surgical education; simulation; assessment

Submitted Nov 04, 2019. Accepted for publication Dec 03, 2019.

doi: $10.21037 /$ jtd.2019.12.69

View this article at: http://dx.doi.org/10.21037/jtd.2019.12.69

Principles of surgical education are more than a century old and have not changed since. But methods for surgical teaching have evolved with time, especially with the advent of the World Wide Web. There are two main novel technologic tools that can be integrated into surgical training:

* Online knowledge sources, such as lectures, webinars, journal clubs, surgical videos, three dimensional planning/printing and anatomic models. These technologies are available everywhere on computers, tablets, cell phones, and allow global access to anyone in the medical field.

* Second important tool is remote skills education. This has been available for a while in laparoscopic surgery. Other than local proctors, remote proctors are also involved and can evaluate or contribute to the training of a surgical colleague from a distant location.
Those new tools are defined as E-learning or online education. Their ultimate goal is to assess the trainees who are using them. Indeed, no educational tool would be validated or widely used without measuring its efficacy and contribution to behavioral change in clinical practice. Thoracic surgery is no stranger to those latest breakthroughs in medical education. In this article, we will review these e-learning tools and analyze their introduction in Thoracic Surgery education.

\section{Online knowledge sources}

William Halsted's legacy in surgery has been marked by his tenets regarding tissue handling, but also three principles in surgical training (1):

* The resident must have intense and repetitive opportunities to take care of surgical patients under the supervision of a skilled surgical teacher; 
* The resident must acquire an understanding of the scientific basis of the surgical disease.

* The resident must acquire skills in patient management and technical operations of increasing complexity with graded enhanced responsibility and independence.

Can these principles be supported by online resources?

One of the first studies on this topic was a multicenter study, published by Gold and colleagues in 2004. The Thoracic Surgery Directors Association Prerequisite Curriculum allowed residents to acquire basic important knowledge before they began their thoracic surgery residency. The content would also serve them as a permanent educational support during and after the completion of formal thoracic surgery residency. The material was presented in the form of a CD-ROM with Internet access; this educational product had relevant media, including videos, photographs, CT-scans, images, multiple-choice/true-false, self-assessment examination and other materials. A randomized study with two groups (one receiving the CD-ROM and the other one an outline of the content of the curriculum, appropriate references, but no educational content) included 69 residents in each group. Among all the residents, regarding self-assessment survey parameters, there was a significant difference favoring the residents who received the CD-ROM both in knowledge, teaching and application of knowledge and in all of the comfort/satisfaction parameters (2). The software had realtime tracking features, allowing instructors to monitor student engagement and success.

In another multicenter study, Antonoff and colleagues chose a topic in which the American Board of Thoracic Surgery applicants performed poorly: tracheal surgery (3). They used Moodle (modular objectoriented dynamic learning environment) software (Moodlerooms, Inc., Baltimore, MD, USA), an open source course management system, also known as a Learning Management System or a Virtual Learning Environment. The software allows quizzes, feedback pages, discussion forums, group projects, and wiki pages, as well as real-time tracking features, allowing instructors to monitor student engagement and success. Four courses were set up:

* Pulmonary physiology and assessment;

- Radiographic and surgical anatomy of the trachea;

* Disorders of the trachea and the bronchus;

* Tracheal and bronchial surgery.

The study group was composed of 19 residents. An average of $1.35(0.18-3.5)$ hours were spent for each course and 6.4 (2.75-9.5) hours for the four courses. Residents passed each quiz after a mean of 2.86 [1-7] attempts. Overall courses were found to be easy to navigate; courses, multimedia content and quizzes were beneficial in learning content (3).

Webinars and online lectures are another source of knowledge. As of 2018, European Society of Thoracic Surgeons organized monthly webinars covering a wide variety of topics, from sublobar resections in lung cancer, simulation in thoracic surgery to esophageal resections. An average of 194 [114-274] surgeons from around the world registered, 90 [55-142] attended the webinars. Replays of the webinars were available and were watched at an average of 70 [53-98] times. An average of 26 [9-53] questions were asked during the webinars and polls were encouraged during the webinars to get feedback from the audience. There's a real interest for online learning resources throughout the world.

Surgical videos are now available everywhere and the standards of such videos are questionable. An international survey on 388 participants in the field of gynecology showed that an ideal surgical teaching video should be 10 to 15 minutes long, provide information on the surgical setup, have clearly defined steps in divided subheadings and with access to the entire non-modified video for reviewers (4). Thoracic surgery is no stranger to this practice: Dr. Robert Cerfolio regularly uploads videos on his YouTube channel, giving tips and tricks to fellow surgeons doing roboticassisted thoracoscopic surgery for lung cancer.

Three-dimensional planning and printing are also becoming tools for pre-operative planning and anatomical understanding. There are several reports of using these technologies in apical tumors, tumors with vertebral invasion, chest wall invasion and tracheobronchial reconstruction (5-8). In a very recent study that involved 16 patients who underwent video-assisted thoracoscopic surgery (VATS) lobectomy, preoperative 3D printing of pulmonary hilum was found to be the most accurate to show the variations of hilar vessels (5). Another case report was on a very difficult patient with right main bronchus carcinoid tumor that required resection and reconstruction of carina and right main bronchus. $3 \mathrm{D}$ CT scan reconstruction allowed accurate recognition of extra-bronchial extent of the tumor and there was a correlation between preoperative and intra-operative findings (6). In another study on chest wall resection and reconstruction, 3D planning and printing technology was applied for primary chest wall tumors and lung cancers with chest wall involvement (7). 
$3 \mathrm{D}$ reconstruction allowed accurate preoperative planning of the possible defect and titanium plates were 3D printed based on this planning. The authors showed less bleeding and pain in 3D planned and reconstructed group $(7,8)$.

In a study carried out among congenital cardiac surgeons, 3D printed models had more impact on the understanding of complex anatomy among residents such as in Tetralogy of Fallot (9). 3D stereoscopic images and digital virtual simulation are now used in the teaching of gross anatomy for medical students and integration of these tools to classical education such as specimen dissection caused a significant increase in the understanding of gross anatomy and outcomes in examinations (10).

\section{Online skills training: simulation and multimedia}

Simulation is becoming an important training tool in surgical fields. Simulation leads to acquisition of surgical skills before advancing to practice on patients and thus affects clinical practice and patient safety (11). A virtual reality VATS lobectomy simulator was developed in 2014 and was used with 100 thoracic surgeons/residents (12). It was found to be realistic with good content. It was initially developed only for right upper lobectomy and now it is available for all lobes. However, it requires physical use of the simulator by the surgeon.

In the current era, tele-simulation is a novel concept that uses the internet to link simulators between an instructor and a trainee in different locations. It was extensively used to teach laparoscopic skills. It was tested in underserved remote places (13). A study involving 16 surgeons in Botswana was carried out. Eight surgeons had simulator practice and watched DVDs on the fundamentals of laparoscopic surgery (FLS). A second group of 8 surgeons had one remote training session per week with an FLS proctor at the University of Toronto who provided feedback and demonstrated proper technique in addition to simulator practice. Tele-simulation group achieved $100 \%$ pass rate, whereas it was only $38 \%$ in the self-trained group (13).

Another study was performed in Chile (14). The participating institutions were $250-750 \mathrm{~km}$ apart from each other. The aim was to test a web-based mobile iOS and Android application (Lapp) which enables a remote studentteacher interaction. Instructors used Lapp to assess videorecorded training sessions of students at distant locations and guide them through the laparoscopic skill course with specific and personalized feedback. Thirty trainees were trained using Lapp and compared with 25 locally taught.
Performance in the Lapp group improved significantly after the course and was found to be as effective as in-person instruction in teaching advanced laparoscopic surgical skills (14).

Even Google Glass (GG) (Mountain View, California) was compared with Skype ${ }^{\mathrm{TM}}$ for its feasibility in scoring the technical skills component of the fundamentals of laparoscopic surgery examination (15). Twenty-eight participants were asked to complete the peg transfer and intracorporeal knot tasks of FLS using both GG and Skype $^{\mathrm{TM}}$ setups. Google Glass (Mountain View, California) was found to be equivalent with Skype ${ }^{\mathrm{TM}}$ and feasible in remote assessment of FLS skills with strong interrater reliability.

A randomized control study from Germany compared multimedia based with practical training, and combination training using either multimedia-based + practical training or no training (control group) (16). Eligible participants were 70 medical doctors (MDs) participating in surgical fellowships. Participants were evaluated by blinded raters using a modified objective structured assessment of technical skills. Multimedia-based training improved surgical performance significantly and was recommended to be included in surgical curriculum.

Last but not least, simulation in e-learning is a great way to promote interdisciplinary teamwork. It is important in thoracic surgery where management of non-small cell lung cancer involves various specialists (pathologist, radiologist, oncologist, pulmonologist and other related specialties) (17). It's in that perspective that engaging an interdisciplinary team for NSCLC (GAIN 3.0) was designed to enhance interdisciplinary collaboration for effective diagnosis, assessment, and treatment. This program consists of a first phase with each participant completing online assessments before attending live programs simulating cancer tumor board. Amongst 416 attendees, there was an overall knowledge increase of $13 \%$ from pre-test to post-test (17).

\section{Online assessment of classical surgical training and E-learning}

As the adage emphasizes, "It is not how much you know but how well you know". Evaluation of any educational initiative is critical to conclude that the new method benefits the trainer and the students and/or residents. However, assessment in the field of surgical science is particularly complex, because E-learning can only validate a theoretical 
part of knowledge. The practical aspect of surgical training remains based on hands-on sessions or on experience acquired in the operating room. Rather than assessing the surface of E-learning course, understanding assessment allows the trainer to gauge the depth of an online learner's comprehension and ability to solve surgical scenario. Basically, there are several ways to track online residents' progress:

(I) Multiple-choice questions or open-ended questions: this is the simplest qualitative online assessment method for learners, allowing the most creative freedom. The only caution is that open-ended questions are difficult to grade and multiple-choice questions can be too restrictive if they are not well written.

(II) Task-based simulations: learners have to use all of their resources and skills to achieve the task. The simulation has to be closer to reality as possible to achieve accurate results. The virtual environment can be enhanced by immersive sounds, videos or images. Trainer can assess the performance of the specific task in specific conditions (such as simulation of major bleeding, surgery under pressure).

(III) Branching scenarios: learners are facing several situations involving multiple decision points. The trainer can assess the different choices highlighting the negative or positive repercussions of their actions.

(IV) Online interviews and online discussion: if direct face-to-face interviews are not possible, online learners can interact with their peers and discuss the topic. Moreover, forums give online learners the possibility to communicate ideas, discuss specific topics, and interact with instructors.

Kirkpatrick's four levels of evaluation are also valid for e-learning (18):

* Level one is related with student/resident reaction and level of satisfaction with the educational activity by the learner;

* Level two relates to learning and the evaluation of knowledge;

* Level three expands on this and considers whether the education has influenced behavior.

* Level four evaluates the impact on outcomes such as improvement in quality of care and best practice application.
Almost all the research in surgical fields is related with level one and two. One of the recent researches leads to development of VATS lobectomy assessment tool (19). Using Delphi method, eight steps were determined for evaluation of competency in VATS lobectomy with over $90 \%$ consensus rate. The follow-up study involved rating 53 participants who performed 106 VATS lobectomies on a virtual reality simulator (20). Rating was performed by 3 raters. The participants' VATS lobectomy experience correlated significantly with their score and a pass/fail score was found. It is obvious that remote certification and competence assessment will become important in minimally invasive thoracic surgery as well.

In order to improve results during the surgical teaching process, trainers also need to implement reliable assessment instruments during theoretical learning. Based on teaching of cardiothoracic surgeons, the Zwisch model has been developed (21). Based on a 4-stage process, the model provides a conceptual framework to help interactions between trainers and trainees in the operating room. The model includes 4 stages:

* Show and tell;

* Smart help;

* Dumb help;

* And no help.

The method consists of dividing a procedure into several components followed by immediate real-time feedback allowing the degree of autonomy of the residents. This method allows to gauge the level of skills acquisition. Application of this model in the online assessment of e-learning seems possible and may open some perspectives on assessment tools. Using a model of orchidopexy, 11 trainees were coached with a dedicated e-learning with the main goal to "how to" assess trainee surgical skills objectively based on classical Zwisch scale (22). The e-learning included 3 modules: (I) core concepts, where assessment tool methods were learnt; (II) learn to assess, where learners watched video clips, explained the assessment method; (III) test phase where leaners rated surgical and global skills as viewed in the video clips. A total of 89 surgical skill ratings were performed. There was a strong and significant difference before and after e-learning process in interclass correlation coefficient and inter-rater reliability consensus between attending. It appears that Zwisch scale would be efficient providing standardized approach for assessment surgical performance even if comprehension has been transmitted by e-learning. 


\section{Conclusions}

E-learning sources are becoming important in thoracic surgical training. Online knowledge resources such as lectures, webinars and VATS lobectomy simulators are already available. These tools and many other novel methods will become an essential part of the curriculum as well.

\section{Acknowledgments}

Funding: None.

\section{Footnote}

Provenance and Peer Review: This article was commissioned by the Guest Editor (Gilbert Massard) for the series "Training in Pulmonary Medicine and Surgery" published in Fournal of Thoracic Disease. The article has undergone external peer review.

Conflicts of Interest: All authors have completed the ICMJE uniform disclosure form (available at http://dx.doi. org/10.21037/jtd.2019.12.69). The series "Training in Pulmonary Medicine and Surgery" was commissioned by the editorial office without any funding or sponsorship. HFB reports personal fees from Johnson and Johnson, outside the submitted work. The authors have no other conflicts of interest to declare.

Ethical Statement: The authors are accountable for all aspects of the work in ensuring that questions related to the accuracy or integrity of any part of the work are appropriately investigated and resolved.

Open Access Statement: This is an Open Access article distributed in accordance with the Creative Commons Attribution-NonCommercial-NoDerivs 4.0 International License (CC BY-NC-ND 4.0), which permits the noncommercial replication and distribution of the article with the strict proviso that no changes or edits are made and the original work is properly cited (including links to both the formal publication through the relevant DOI and the license). See: https://creativecommons.org/licenses/by-nc-nd/4.0/.

\section{References}

1. Nguyen L, Brunicardi FC, Dibardino DJ, et al. Education of thes modern surgical resident: Novel approaches to learning in the era of the 80-hour workweek. World J Surg 2006;30:1120-7.

2. Gold JP, Begg WB, Fullerton D, et al. Successful implementation of a novel internet hybrid surgery curriculum: the early phase outcome of thoracic surgery prerequisite curriculum e-learning project. Ann Surg 2004;240:499-507.

3. Antonoff MB, Verrier ED, Yang SC, et al. Online learning in thoracic surgical training: promising results of multi-institutional pilot study. Ann Thorac Surg 2014;98:1057-63.

4. Chauvet $\mathrm{P}$, Botchorishvili R, Curinier S, et al. What Is a Good Teaching Video? Results of an Online International Survey. J Minim Invasive Gynecol 2020;27:738-47.

5. Smelt JLC, Suri T, Valencia O, et al. Operative Planning in Thoracic Surgery: A Pilot Study Comparing Imaging Techniques and Three-Dimensional Printing. Ann Thorac Surg 2019;107:401-6.

6. Betser L, De Wolf J, Glorion M, et al. Use of 3-dimensional computed tomography for planning a complex sleeve bronchoplasty with total parenchymasparing resection of a carcinoid tumour in the right main bronchus. Interact Cardiovasc Thorac Surg 2019;29:638-40.

7. Wu Y, Chen N, Xu Z, et al. Application of 3D printing technology to thoracic wall tumor resection and thoracic wall reconstruction. J Thorac Dis 2018;10:6880-90.

8. Gillaspie EA, Matsumoto JS, Morris NE, et al. From 3-Dimensional Printing to 5-Dimensional Printing: Enhancing Thoracic Surgical Planning and Resection of Complex Tumors. Ann Thorac Surg 2016;101:1958-62.

9. White SC, Sedler J, Jones TW, et al. Utility of threedimensional models in resident education on simple and complex intracardiac congenital heart defects. Congenit Heart Dis 2018;13:1045-9.

10. Deng X, Zhou G, Xiao B, et al. Effectiveness evaluation of digital virtual simulation application in teaching of gross anatomy. Ann Anat 2018;218:276-82.

11. Rowse PG, Dearani JA. Deliberate Practice and the Emerging Roles of Simulation in Thoracic Surgery. Thorac Surg Clin 2019;29:303-9.

12. Jensen K, Bjerrum F, Hansen HJ, et al. A new possibility in thoracoscopic virtual reality simulation training: development and testing of a novel virtual reality simulator for video-assisted thoracoscopic surgery lobectomy. Interact Cardiovasc Thorac Surg 2015;21:420-6.

13. Okrainec A, Henao O, Azzie G. Telesimulation: an 
effective method for teaching the fundamentals of laparoscopic surgery in resource-restricted countries. Surg Endosc 2010;24:417-22.

14. Quezada J, Achurra P, Jarry C, et al. Minimally invasive tele-mentoring opportunity-the mito project. Surg Endosc 2020;34:2585-92.

15. Nikouline A, Jimenez MC, Okrainec A. Feasibility of remote administration of the fundamentals of laparoscopic surgery (FLS) skills test using Google wearable device. Surg Endosc 2020;34:443-9.

16. Pape-Koehler C, Immenroth M, Sauerland S, et al. Multimedia-based training on Internet platforms improves surgical performance: a randomized controlled trial. Surg Endosc 2013;27:1737-47.

17. Murgu S, Rabito R, Lasko G, et al; GAIN collaborators. Impact of a Non-small Cell Lung Cancer Educational Program for Interdisciplinary Teams. Chest 2018;153:876-87.

Cite this article as: Batirel HF, Assouad J, Etienne H, D'Journo XB. Auditorium of the future: e learning platform. J Thorac Dis 2021;13(3):2038-2043. doi: 10.21037/jtd.2019.12.69
18. Kirkpatrick DL. Evaluating training programs: The four levels. San Francisco, CA: Berrett-Koehler, 1994.

19. Jensen K, Petersen RH, Hansen HJ, et al. A novel assessment tool for evaluating competence in videoassisted thoracoscopic Surgery lobectomy. Surg Endosc 2018;32:4173-82.

20. Jensen K, Hansen HJ, Petersen RH, et al. Evaluating competency in video-assisted thoracoscopic surgery (VATS) lobectomy performance using a novel assessment tool and virtual reality simulation. Surg Endosc 2019;33:1465-73.

21. DaRosa DA, Zwischenberger JB, Meyerson SL, et al. A theory-based model for teaching and assessing residents in the operating room. J Surg Educ 2013;70:24-30.

22. Fernandez N, Maizels M, Farhat W, et al. E-learning teaches attendings "how to" objectively assess pediatric urology trainees' surgery skills for orchiopexy. J Pediatr Urol 2018;14:132.e1-132.e6. 